\title{
Staff training influence on non-invasive ventilation outcome for acute hypercapnic respiratory failure
}

\author{
J.L. Lopez-Campos, C. Garcia Polo, A. Leon Jimenez, A. Arnedillo, \\ E. Gonzalez-Moya, J.J. Fenandez Berni
}

ABSTRACT: Staff training influence on non-invasive ventilation outcome for acute hypercapnic respiratory failure. J.L. Lopez-Campos, C. Garcia Polo, A. Leon Jimenez, A. Arnedillo, E. Gonzalez-Moya, J.J. Fenandez Berni.

Background. Although non-invasive ventilation (NIV) efficacy in the treatment of acute hypercapnic respiratory failure (AHRF) have been previously demonstrated, not all the studies reveal this fact in the same degree, with some variability in the results. This study aimed to analyse variables related to NIV outcome for AHRF.

Methods. A group of consecutive patients requiring NIV due to AHRF were included in a prospective observational cohort study performed in conventional wards. Variables considered included those reported in the literature, as well as staff problems during the management of the ventilators. The study aimed to include all patients during one year, but after the initial results, it had to be suspended.

Results. Fifteen patients were included in the study: 10 males, mean age $68 \pm 12$. APACHE-II score was $17.6 \pm 6.5$. $\mathrm{pH}$ and $\mathrm{pCO}_{2}$ before NIV were $7.22 \pm 0.11$ and $110 \pm 72 \mathrm{mmHg}$ respectively. pH, corticosteroids use, APACHE score, and EPAP were found to influence outcome. Besides, an inadequate use of NIV due to lack of personnel training was detected in all patients with NIV failure (RR 3.5; 95\% CI: 1.08-11.2; $p=0.007)$. In the light of these results, the study had to be suspended and patients were transferred to the respiratory ward.

Conclusions. NIV is a life-saving respiratory treatment influenced by several factors, of which staff training is a key one. Centres attending acute respiratory patients should have an area in which this requirement is fulfilled. Monaldi Arch Chest Dis 2006; 65: 3, 145-151.

Keywords: Acute respiratory failure, medical staff, noninvasive ventilatory support, nursing staff, prognosis.

Sección de Neumología y Alergia. Hospital Universitario Puerta del Mar. Cádiz. Spain.

Correspondence: Jose Luis Lopez-Campos; Avda. Reina Mercedes, 35 - 6º 41012 Seville, Spain; e-mail: lcampos@separ.es

\section{Introduction}

Non-invasive ventilation (NIV) has demonstrated its efficacy in the treatment of acute hypercapnic respiratory failure (AHRF) due to chronic obstructive pulmonary disease (COPD) exacerbations throughout a good number of randomised controlled trials and meta-analysis $[1,2]$. Likewise, NIV has a role in the treatment of AHRF resulting from other causes [3]. Although most studies present a trend towards the improvement of patients with this therapy, not all the studies demonstrate this result in the same degree, with some variability in the results. According to the different controlled trials published success rates range between $75-100 \%$ for COPD and $20-70 \%$ for nonCOPD patients. During the past decades several factors have been pointed out to explain this variability in outcome [4] such as the degree of encephalopathy, several severity of disease indexes, i.e. Acute Physiology and Chronic Health Evaluation (APACHE) II score [5] or Simplified Acute Physiology Score (SAPS II) [6], arterial blood gases ( $\mathrm{pH}$ or $\mathrm{pCO}_{2}$ at admission and after a few hours of ventilation), or respiratory rate. Furthermore, all these variables might be influenced by patient's tolerance to NIV, which is directly related to the staff's training and experience on NIV [7]. In this context, we undertook an observational study in order to see the influence of variables related to NIV success in our population. Nonetheless, a preliminary analysis of the results was performed after two months and in the light of the results the study had to be suspended. The results of this preliminary study and the reasons for this decision are presented here.

\section{Methods}

The study was designed as an observational prospective cohort study. It was carried out at "Puerta del Mar" University Hospital (750 beds, population: 227,141), Cadiz, Spain. In this hospital NIV is used either in the intensive care setting, the emergency department, or the conventional ward for more than 10 years, there being no specific unit for noninvasively ventilating or monitoring patients. The study population was a group of consecutive patients requiring NIV due to AHRF during one year starting October 2004. Inclusion criteria were: adult patients attending the emergency department during the period of study with AHRF 
( $\mathrm{pH}<7.35$ and $\mathrm{pCO}_{2}>55 \mathrm{mmHg}$ ) and those with AHRF and a do-not-intubate order. Exclusion criteria were: the need of endotracheal intubation (ETI) or Intensive Care Unit (ICU) admission for treatment or monitoring (hemodynamic instability, multiorganic failure, cardiorrespiratory arrest), and the inability of the patient to collaborate with NIV (severely low level of consciousness, anatomic abnormality which interferes with mask fitting, refusal of patient to receive NIV).

NIV was started as soon as the inclusion criteria were met in all cases. Before initiating NIV, oral consent was obtained from the patient or the next of kin. All ventilation was carried out in conventional wards. Since it was an observational study, randomization was not required. As a first choice, patients were transferred to the respiratory ward and secondly to any internal medicine ward when there was no bed available. The main difference regarding this decision is that although all staff in our hospital was once sufficiently trained to assist ventilatory-dependent patients, only personnel on the respiratory ward are really experienced in ventilators management, since there is no continued training programme for medical and paramedical staff. The rest of the features of respiratory and medical wards in terms of number of doctors, nurses, monitoring, or operative flow charts were similar between them. Additionally, standard medical therapy consisting in corticosteroids, bronchodilators, antibiotics, subcutaneous fractionated heparin, and gastric protectors was also used in both wards as well as any medication needed to treat any existing co-morbidity. Patients were followed-up until discharge or exitus. During their stay patients were evaluated before the initiation of NIV, one hour after NIV onset and then every 24 hours. Besides, there was a physician on call in case the patient deteriorated.

Variables recorded in each evaluation were the following: previous medical records (age, sex, smoking habit, previous medical diseases, home oxygen therapy or mechanical ventilation, and number of admissions or acute ventilatory support episodes in the previous year), data upon admission (cause of exacerbation, APACHE-II, accessory muscle use, copious secretions, mental status, initial pharmacological treatment, and the ward where patient was ventilated), complementary studies (blood count and biochemistry, arterial blood gases, and condensation on chest radiography) and data regarding ventilation (time spent to establish NIV, device and masks for NIV, ventilatory parameters, presence of complications, adverse effects, total ventilation time, days of stay, inadequate use of NIV as defined below). The cause of exacerbation was classified as infection, congestive heart failure (CHF) or unknown/other. Infection was considered as the cause of admission when the sputum was purulent and white cell count was above 11,500 cells $/ \mathrm{mm}^{3}$. Mental status was measured by both Brochard et al. [8] scale (0 normal; 1 mild asterixis; 2 marked asterixis, mild confusion, or sleepiness during the day; 3 major confusion with daytime sleepiness or agitation; and 4 obtundation or major agitation) and Glasgow coma scale (GCS) [9]. All data were recorded by a lung physician experienced in NIV. After two months of study, a preliminary analysis of the results was performed and the study had to be suspended.

\section{Ventilation procedure}

Ventilation procedure was adopted from British Thoracic Society (BTS) guidelines [10]. Noninvasive pressure support ventilation was used in all cases. NIV was delivered by two noninvasive mechanical ventilators: Sullivan VPAP- II ST (Resmed Ltd., Abingdon, Oxfordshire, UK) and Saime VS Serena (Saime, Sanigvy le Temple, France). Oro-nasal masks (Respironics, Pittsburgh, Pa., USA) were used in all cases with three possible sizes (large, medium and small). Ventilation was then initiated in the ST mode with the following parameters: IPAP $10 \mathrm{~cm} \mathrm{H}_{2} \mathrm{O}$, EPAP $4 \mathrm{~cm} \mathrm{H}_{2} \mathrm{O}$, backup rate $10-15 \mathrm{rpm}$. For COPD patients IPAP was increased during the next minutes in $1 \mathrm{~cm} \mathrm{H}_{2} \mathrm{O}$ amounts every 5 minutes until the patient experimented discomfort or leaks appeared and EPAP was established between 4-6 $\mathrm{cm} \mathrm{H}_{2} \mathrm{O}$ according to the patient's tolerance. For restrictive patients IPAP was established similarly but EPAP was increased by $1 \mathrm{~cm} \mathrm{H}_{2} \mathrm{O}$ amounts every 5 minutes until oxygen saturation was $90 \%$ or discomfort or leaks appeared. In those cases with oxygen saturation below $90 \%$ after parameters adjustment, supplemental oxygen was administered via oro-nasal mask.

During the first 24 hours, patients were encouraged to use NIV for as long as tolerated aiming for 20 hours, with periods of relief for meals, conversation, comfort, and respiratory treatments as necessary. During relief periods oxygen was administered via nasal prongs to maintain oxygen saturation of $90 \%$. The following days NIV use was progressively decreased according to patient's improvement. NIV was discontinued once clinical stability was achieved as defined below or if the patient refused to continue or met ETI criteria (see below).

\section{Definitions}

Treatment failure. As defined by BTS consensus guideline (10): deterioration in patient's condition, failure to improve or deterioration in arterial blood gas tensions, development of new symptoms or complications that require ETI or ICU admission, or deteriorating conscious level.

Early failure. Failure of NIV before 48 hours of ventilation or without initial success.

Late failure. Failure of NIV after more than 48 hours of NIV with initial success.

Treatment success. Improvement in patient's condition and gas exchange so that mechanical ventilation can be successfully removed with clinical stability.

Clinical stability. As defined by Kramer et al. [11]: respiratory rate $\leq 24 \mathrm{rpm}$, heart rate $\leq 110 \mathrm{spm}$, $\mathrm{pH} \geq 7,35$ and $\mathrm{SatO}_{2}>90 \%$ with oxygen $\leq 3 \mathrm{lpm}$. 
Complications. A non-expected clinical event which deteriorates the expected progression of the patient, such as nosocomial pneumonia or sepsis, pulmonary embolism, acute renal failure, shock, metabolic complications, or hepatic dysfunction.

NIV misuse event. An event regarding the ventilator use that was considered to be wrong according to the instructions of the device or the indications by the physician in charge. Every 24 hours staff was inquired about the use of NIV, such as the parameter settings, or alarms management. All events indicating an inadequate use of the ventilator were noted.

Adverse effects. Events directly related to noninvasive ventilation use, such as nasal bridge ulceration, discomfort, excessive noise of the device, or excessive leaks.

Endotracheal intubation criteria. As defined by Brochard et al. [8], the presence of one major criterion or two minor criteria was considered to indicate the need for ETI. Major criteria were: respiratory arrest, respiratory pauses with loss of consciousness or gasping for air, psychomotor agitation making nursing care impossible and requiring sedation, a heart rate below 50 beats per minute with loss of alertness, and hemodynamic instability with systolic arterial blood pressure below $70 \mathrm{~mm} \mathrm{Hg}$. Mi- nor criteria were: respiratory rate above 35 breaths per minute and above the value on admission; an arterial $\mathrm{pH}$ value below 7.30 and below the value on admission; a value for the partial pressure of arterial oxygen below $45 \mathrm{~mm} \mathrm{Hg}$, despite oxygen therapy; and an increase in the score for encephalopathy.

\section{Statistics}

For descriptive purposes, absolute and relative frequencies were used to describe qualitative variables, and mean \pm standard deviation were used for quantitative ones. In the comparative analysis, non-parametric tests were used. Comparison between quantitative variables was assessed by Mann-Whitney U test whereas Chi-square test or Fisher's exact test were used to compare qualitative variables and to calculate relative risks with $95 \%$ confidence intervals. Due to the low number of patients included, a multivariate analysis could not be performed. Alpha error was set at 0.05 .

\section{Results}

From October to December 200415 patients were included in the study: 10 males and 5 females, mean age $68 \pm 12$ years (table 1 ; success

Table 1. - Descriptive data of the patients

\begin{tabular}{|c|c|c|c|c|c|c|c|c|c|}
\hline $\mathbf{n}$ & Sex & Age & Disease & APACHE & pH & $\mathrm{pCO}_{2}$ & $\begin{array}{l}\text { Ward } \\
\text { events* }\end{array}$ & NIV misuse & Result \\
\hline 1 & M & 65 & COPD & 23 & 7.29 & 70.3 & Other & No & Discharge \\
\hline 2 & M & 67 & TBC & 19 & 7.21 & 124 & Other & Yes & Exitus \\
\hline 3 & $\mathrm{~F}$ & 84 & OHS & 23 & 7.28 & 100 & Other & Yes & ETI - ICU \\
\hline 4 & M & 72 & COPD & 21 & 7.21 & 166 & Respir & No & Discharge \\
\hline 5 & M & 68 & OSAS-CHF & 22 & 7.24 & 65 & Other & Yes & Exitus \\
\hline 6 & $\mathrm{~F}$ & 80 & $\mathrm{TC}$ & 13 & 7.32 & 84 & Other & No & Discharge \\
\hline 7 & M & 72 & COPD & 10 & 7.27 & 85 & Respir & Yes & Discharge \\
\hline 8 & M & 70 & COPD & 11 & 7.31 & 95 & Respir & Yes & Discharge \\
\hline 9 & M & 49 & COPD & 14 & 7.18 & 108.5 & Respir & No & Discharge \\
\hline 10 & M & 75 & COPD & 11 & 7.29 & 57.4 & Respir & No & Discharge \\
\hline 11 & $\mathrm{~F}$ & 32 & CAP-HIV & 18 & 7.14 & 81 & Other & Yes & Exitus \\
\hline 12 & M & 75 & COPD & 17 & 7.27 & 79 & Respir & No & Discharge \\
\hline 13 & $\mathrm{~F}$ & 74 & OSAS & 11 & 7.29 & 85 & Respir & No & Discharge \\
\hline 14 & M & 79 & COPD & 18 & 7.26 & 100 & Respir & No & Discharge \\
\hline 15 & F & 70 & Asthma-BQ & 34 & 6.87 & 354 & Respir & Yes & Exitus \\
\hline
\end{tabular}

Failures appear in grey. COPD: Chronic obstructive pulmonary disease. OSAS: Obstructive sleep apnea syndrome. CHF: Congestive heart failure. TC: Thoracic cage. CAP: Community acquired pneumonia. HIV: Human immunodeficiency virus. BQ: bronchiectasis. Respir: respiratory ward. ICU: Intensive care unit. pH: pH before NIV. ETI: endotracheal intubation. OHS: Obesity-hypoventilation syndrome. NIV: non-invasive ventilation. * As defined in the text. 
group $n=10$, failure group $n=5$ ). Smoking habits included 3 current smokers, 7 ex-smokers, and 5 non-smokers. Previous medical history included systemic hypertension $7(46,7 \%)$ patients, diabetes $3(20 \%)$ patients, hypercholesterolemia $4(26,7 \%)$ patients, and heart problems $10(66,7 \%)$ patients. None of the patients had received mechanical ventilation for an acute exacerbation before, but 2 of them were receiving home pressure support mechanical ventilation, 4 of them were on a domiciliary oxygen therapy program, and 3 used home nebulizers. The number of admissions during the previous year ranged from 0 to 3 (mean $0.92 \pm$ 1.1). The most frequent cause of the exacerbation was infection in $9(60 \%)$ patients. APACHE-II score was $17.6 \pm 6.5$ with a predicted mortality of $24.1 \pm 17.4 \%$. $\mathrm{pH}$ and $\mathrm{pCO}_{2}$ before NIV were 7.22 \pm 0.11 and $110 \pm 72 \mathrm{mmHg}$ respectively (table 1 ). Seven $(46.7 \%)$ patients used accessory musculature and also seven patients had copious secretions. All patients could expectorate adequately. The most frequent mental status according to Brochard et al. scale [8] was mild asterixis (6 patients; 40\%), followed by marked asterixis, mild confusion, or sleepiness during the day (3 patients; $20 \%$ ) and major confusion with daytime sleepiness or agitation (3 patients; 20\%). GCS was $12.6 \pm 4$ points. Severity of patients ventilated in the respiratory ward compared to those ventilated elsewhere was found not to be significantly different in terms of $\mathrm{pH}(7.2 \pm 0.13$ vs. $7.2 \pm 0.06 ; \mathrm{p}=$ $0.859)$ and APACHE score $(16.2 \pm 7.7$ vs. $19.6 \pm$ $3.8 ; \mathrm{p}=0.08)$.

Sullivan VPAP-II was used in 5 patients and Saime VS Serena in 10. Time elapsed between blood gas test result and the initiation of NIV was $113 \pm$ 134 minutes. Time used to establish final parameters was $40 \pm 14$ minutes. We found no significant differences in timing between ventilators (Sullivan
VPAP-II $43 \pm 13$ minutes vs. Saime VS Serena 37.5 \pm 15.7 minutes; $\mathrm{p}=0.537)$. Ventilatory parameters were IPAP $13.5 \pm 3.5$, EPAP $5.5 \pm 1.2$ and backup rate $12.3 \pm 1.6$. There were no significant differences in ventilatory parameters according to the ventilator used (IPAP $13.4 \pm 4$ vs. $13.8 \pm 2.5, \mathrm{p}=0.797$; EPAP $5.1 \pm 0.9$ vs. $6.2 \pm 1.4, p=0.147$; backup rate $12.5 \pm$ 1.6 vs. $12.2 \pm 1.7, \mathrm{p}=0.833)$. However, COPD patients tended to had a lower EPAP (COPD: $4.8 \pm 0.6$ vs. non-COPD $6.14 \pm 1.3 ; \mathrm{p}=0.073$ ). Patients were ventilated for $4 \pm 4.6$ days, with $38 \pm 44$ hours of ventilation. Mean stay was $15 \pm 11$ days.

Adverse effects were: nasal bridge ulceration (1 patient), eye irritation (1 patient), excessive noise of the device (1 patient), and discomfort (2 patients). There were no complications during the follow-up. Significant variables and relative risks appear in table 2 and table 3. Relative risk of NIV success could not be calculated for EPAP since none of the patients with EPAP $>7 \mathrm{cmH}_{2} \mathrm{O}$ improved, but the relative risk to fail NIV with EPAP $<7 \mathrm{cmH}_{2} \mathrm{O}$ was 5.5 (95\% CI: 1.5-19.2).

There was one late failure (patient number 5) and 4 early ones. Only one patient underwent ETI, since the other failures had a do-not-intubate order. Failure rate was $33.3 \%$. Failure rate rose up to $71.4 \%$ (table 1, table 2 ) in the subgroup of patients with an inadequate use of NIV, whereas in the rest of the sample all patients improved with NIV. Similarly, failure rate was $11.1 \%$ in the subgroup of patients ventilated in the respiratory ward versus $66.7 \%$ for those ventilated elsewhere (table 1, table 2). Problems detected regarding the use of NIV are summarized in table 4 . These results suggested that personnel lack of skill significantly influenced prognosis, so the study was suspended to transfer patients to the respiratory ward where a trained staff is in charge of noninvasively ventilated patients.

Table 2. -Comparison of most important variables between groups. Qualitative variables are expressed in absolute an relative frequencies. Quantitative variables are expressed in mean \pm standard deviation

\begin{tabular}{lccc}
\hline Variable & $\begin{array}{c}\text { Success group } \\
\mathbf{N}=\mathbf{1 0}\end{array}$ & $\begin{array}{c}\text { Failure group } \\
\mathbf{N}=\mathbf{5}\end{array}$ & $\mathbf{p}$ \\
\hline NIV misuse & $2(20 \%)$ & $5(100 \%)$ & 0.007 \\
\hline Respiratory ward & $8(80 \%)$ & $1(20 \%)$ & 0.089 \\
\hline COPD & $8(80 \%)$ & $0(0 \%)$ & 0.007 \\
\hline Open eyes spontaneously & $10(100 \%)$ & $3(60 \%)$ & 0.095 \\
\hline Glasgow & $14 \pm 2.3$ & $9.8 \pm 5.4$ & 0.055 \\
\hline pH before NIV & $7.26 \pm 0.04$ & $7.14 \pm 0.16$ & 0.042 \\
\hline pH after 1 h ventilation & $7.36 \pm 0.07$ & $7.17 \pm 0.08$ & 0.004 \\
\hline Corticosteroids & $9(90 \%)$ & $2(40 \%)$ & 0.039 \\
\hline APACHE & $14.8 \pm 4.7$ & $23.2 \pm 6.3$ & 0.019 \\
\hline EPAP & $4.89 \pm 0.7$ & $6.6 \pm 1.1$ & 0.019 \\
\hline
\end{tabular}


Table 3. - Relative risks of NIV success for significant variables

\begin{tabular}{lcccc}
\hline Variable & & Relative risk & 95\% confidence interval & p \\
\hline NIV inadequate use & Yes & 1 & $1.08-11.2$ & 0.007 \\
& No & 3.5 & $1.08-11.2$ & 0.007 \\
\hline COPD & Yes & 3.5 & & 0.042 \\
\hline pH before NIV & $>7.29$ & 1 & $1.07-3.7$ & 0.023 \\
\hline pH after 1 h ventilation & $>7.30$ & 2 & $1-35.9$ & 0.039 \\
\hline Corticosteroids use & $<7.30$ & 1 & & $1.04-16.3$ \\
& Yes & 6 & & 0.026 \\
\hline APACHE & No & 1 & 1 & $1.09-6.5$ \\
\hline
\end{tabular}

Table 4. - Main problems encountered during follow-up. Percentages are referred to total number of patients

\begin{tabular}{lc}
\hline Problems & Number of patients: n (\%) \\
\hline The ventilator was not used during that shift because the staff didn't know how to operate the ventilator & $6(40 \%)$ \\
\hline Bad mask fitting with excessive leaks & $3(20 \%)$ \\
\hline Personnel didn't know how to control oxygen therapy. High flow rates & $1(6.6 \%)$ \\
\hline The ventilator was not connected because oxygen saturation was $\geq 90 \%$ while receiving oxygen & $1(6.6 \%)$ \\
\hline Ventilator was reconnected after a resting period without expiratory valve & $1(6.6 \%)$ \\
\hline Personnel didn't know how to deal with ventilator alarms & $1(6.6 \%)$ \\
\hline The patient was not under close observation. The ventilator disconnected and no one noticed & $1(6.6 \%)$
\end{tabular}

\section{Discussion}

The aim of this study was to determine variables related to NIV outcome. Success rates are influenced by many factors, among which the clinician team's training and experience is a key one [7]. Our findings suggest that the use of NIV by an inexperienced personnel leads to a high failure rate, which led to the suspension of the study. The use of NIV outside the ICU permits clinicians perform an early intervention to prevent further respiratory deterioration, it gives access to respiratory support for patients who would not otherwise be admitted to the ICU, and supply ventilatory support in a less intimidating environment [12]. Nonetheless, the location chosen for patients receiving NIV should include factors such as adequate monitoring, and staff skill and experience in the procedure, the equipment and the potential complications [12].
Although all staff was once trained to assist patients, in our hospital there is no continued training programme for medical and paramedical staff, and only personnel on the respiratory ward is used to work with ventilated patients whereas the rest of the staff work with ventilators only occasionally. This makes a considerable difference in experience between both settings. Medical and paramedical staff expertise is a variable difficult to measure which directly influences outcome and which has been poorly studied so far. The most recent study by Carlucci et al. [13] showed that, over time, a better staff training allows the treatment of more severe and a greater number of patients without significantly changing the rate of success. These authors suggested that with greater staff training and experience, more severely ill patients may be treated with a lower risk of failure. Soo Hoo et al. [14] in a small study (14 episodes in 12 patients, success rate $50 \%$ ), found that there were no differ- 
ences in age, prior pulmonary function, baseline arterial blood gas tensions, admission arterial blood gas tensions, or respiratory rate between those patients successfully treated and those who failed NIV. Nonetheless, the authors found that those patients unable to coordinate with the ventilator or to minimize leaks failed NIV.

Success rate in our study was similar to those published in previous studies with various forms of AHRF [15, 16, 17]. Nonetheless, in our series $\mathrm{pH}$ upon admission was lower than that reported in the largest study performed in ward [15]. In this study it was found that COPD subgroup with $\mathrm{pH}$ below 7.30 might not benefit from NIV. Although $\mathrm{pH}$ before NIV is related to the severity of the patient's condition and thus influences prognosis [18], in our experience it is $\mathrm{pH}$ after a few hours of ventilation, one hour in our case, rather than $\mathrm{pH}$ before ventilation what really influences prognosis (table 2, table 3 ). So we believe that in clinical practice if patients meet NIV criteria, a first trial with NIV should be started with a prompt evaluation after one hour of NIV in order to decide whether to continue NIV or not. Similar results can be drawn from a recent study by Confalonieri et al. [4]. These authors demonstrated that $\mathrm{pH}<7.25$ after two hours of NIV increased failure risk $>90 \%$ with an odds ratio of 21.02 (10.07-43.87), whereas $\mathrm{pH}$ upon admission represented a less striking increase in failure risk with an odds ratio of $1.97(1.23-3.15)$ in the logistic regression model.

Timing is an additional factor which was considered in this study. We recorded three timing periods: time elapsed before admission, time between the result of the blood gas analysis and the initiation of NIV, and time employed in establishing ventilatory parameters. In our case, none of these periods turned out to be a factor influencing prognosis, but larger studies might show different results.

Optimal inspiratory pressures have not been established for NIV, there being studies with both similar and higher IPAP than ours [17, 19]. Lower pressures ensure a better tolerability with fewer adverse effects. Nonetheless, since this study was not designed to assess this matter, further studies should be carried out to establish possible pressures cut-off points. Expiratory pressure was found to be different between groups and close to the level of significance, probably because titration in restrictive patients included a higher EPAP than in COPD. Similarly, differences encountered in corticosteroids treatment are probably associated with COPD subgroup which is related to a better prognosis. It would have been desirable to have a multivariate analysis to assess these differences. However, due to the low number of patients, this type of analysis could not be performed.

Variables related to level of consciousness (open eyes spontaneously, and GCS; table 2) and the ward where NIV was carried out were close to statistical significance, which probably denotes a problem with the number of patients included in this study. In Confalonieri et al. study [4] GCS was significantly associated with outcome with an odds ratio of 2.29 (95\% confidence interval: 1.41-3.72) for GCS between 12-14 and an odds ratio of 4.40 (95\% confidence interval: 2.59-7.49) for GCS $\leq 11$ points.

Of the 5 patients who failed, 4 were early failures and 1 was a late one. Most of the studies report an incidence of late failure of about 10-20\%. The recognition of this subset of patients with a late failure is critical because prolonged application of NIV may delay the time of intubation [20]. This group of late failures have been described to have significantly lower activities of daily living scores, lower blood pressure, more tachycardia and are more likely to have associated complications, such as hyperglycaemia. But the key point is that this is a subgroup of patients particularly associated with poor outcomes, and patients should be rapidly considered for intubation since their mortality rate is $92 \%$ if NIV is continued, whereas mortality decreases to 53\% if they are intubated. In our case, the patient deteriorated rapidly and died in the next few hours.

In conclusion, NIV is a life-saving respiratory treatment for AHRF which is influenced by several factors that should be controlled to guarantee the success of the therapy. One decisive factor is the control of ventilatory support by personnel with sufficient time and experience. Centres attending acute respiratory patients should have an area in which this requirement is fulfilled.

Acknowledgements: The authors of this manuscript are thankful to Richard Nicholas Callaway (Institute of Languages, University of Seville) for the linguistic revision of the manuscript and editorial assistance.

\section{References}

1. Lightowler JV, Wedzicha JA, Elliott MW, Ram FS. Noninvasive positive pressure ventilation to treat respiratory failure resulting from exacerbations of chronic obstructive pulmonary disease: Cochrane systematic review and meta-analysis. BMJ 2003; 326 (7382): 185-187.

2. Fernandez Guerra J, Lopez-Campos Bodineau JL, et al. [Non invasive ventilation for acute exacerbation of chronic obstructive pulmonary disease: a meta-analysis]. Med Clin (Barc) 2003; 120: 281-286.

3. Mehta S, Hill NS. Noninvasive ventilation. Am J Respir Crit Care Med 2001; 163: 540-577.

4. Confalonieri M, Garuti G, Cattaruzza MS, et al. Italian noninvasive positive pressure ventilation (NPPV) study group. A chart of failure risk for noninvasive ventilation in patients with COPD exacerbation. Eur Respir $J$ 2005; 25: 348-355.

5. Knaus WA, Draper EA, Wagner DP, Zimmerman JE. APACHE II: a severity of disease classification system. Crit Care Med 1985; 13: 818-829.

6. Le Gall JR, Lemeshow S, Saulnier F. A new Simplified Acute Physiology Score (SAPS II) based on a European/North American multicenter study. JAMA 1993; 270 (24): 2957-2963.

7. Nava S, Ceriana P. Causes of failure of noninvasive mechanical ventilation. Respir Care 2004; 49: 295-303.

8. Brochard L, Mancebo J, Wysocki M, et al. Noninvasive ventilation for acute exacerbations of chronic obstructive pulmonary disease. $N$ Engl J Med 1995; 333: 817 822 . 
9. Teasdale G, Jennett B. Assessment and prognosis of coma after head injury. Acta Neurochir (Wien) 1976; 34: 45-55.

10. British Thoracic Society Standards of Care Committee. Non-invasive ventilation in acute respiratory failure. Thorax 2002; 57: 192-211.

11. Kramer N, Meyer TJ, Meharg J, Cece RD, Hill NS. Randomized, prospective trial of noninvasive positive pressure ventilation in acute respiratory failure. Am $J$ Respir Crit Care Med 1995; 151: 1799-806.

12. International Consensus Conferences in Intensive Care Medicine: noninvasive positive pressure ventilation in acute respiratory failure. Am J Respir Crit Care Med 2001; 163: 283-291.

13. Carlucci A, Delmastro M, Rubini F, Fracchia C, Nava $\mathrm{S}$. Changes in the practice of non-invasive ventilation in treating COPD patients over 8 years. Intensive Care Med 2003; 29: 419-425.

14. Soo Hoo GW, Santiago S, Williams AJ. Nasal mechanical ventilation for hypercapnic respiratory failure in chronic obstructive pulmonary disease: determinants of success and failure. Crit Care Med 1994; 22: 1253-1261.

15. Plant PK, Owen JL, Elliott MW. Early use of non-invasive ventilation for acute exacerbations of chronic ob- structive pulmonary disease on general respiratory wards: a multicentre randomised controlled trial. Lancet 2000; 355 (9219): 1931-1935.

16. Antonelli M, Conti G, Rocco M, et al. A comparison of noninvasive positive-pressure ventilation and conventional mechanical ventilation in patients with acute respiratory failure. $N$ Engl J Med 1998; 339: 429-435.

17. Martin TJ, Hovis JD, Costantino JP, et al. A randomized, prospective evaluation of noninvasive ventilation for acute respiratory failure. Am J Respir Crit Care Med 2000; 161: 807-813.

18. Ambrosino N, Foglio K, Rubini F, Clini E, Nava S, Vitacca M. Non-invasive mechanical ventilation in acute respiratory failure due to chronic obstructive pulmonary disease: correlates for success. Thorax 1995; 50: 755757.

19. Brochard L, Mancebo J, Wysocki M, et al. Noninvasive ventilation for acute exacerbations of chronic obstructive pulmonary disease. $N$ Engl J Med 1995; 333: 817 822.

20. Moretti M, Cilione C, Tampieri A, Fracchia C, Marchioni A, Nava S. Incidence and causes of non-invasive mechanical ventilation failure after initial success. Tho$\operatorname{rax} 2000$; 55: 819-825.

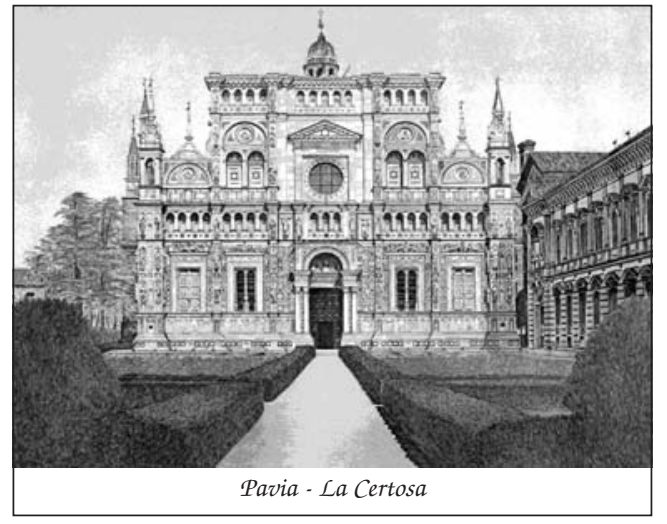

